\title{
The effect of type of firearm and shooting distance on pattern distribution, particle dispersion and amount of gunshot residue
}

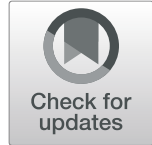

\author{
Zainiharyati Mohd Zain ${ }^{*}$, Siti Nurhazlin Jaluddin ${ }^{1}$, Mohamed Izzharif Abdul Halim ${ }^{1}$ and \\ Mohamed Sazif Mohamed Subri ${ }^{2}$
}

\begin{abstract}
Background: Evidence can be defined as the object's availability and/or information that indicates whether a belief or proposition is true or valid. Gunshot residue (GSR) is an important evidence that can serve many roles in ballistic investigation such as shooting distance, type of firearm and ammunition used in shooting related to GSR. However, due to minimal amount of GSR that can be found in crime scene, suitable methods and technique are required in order to obtain the information from the evidence. This action is also known as evidence recovery. When a firearm is fired, soot or particles are discharged from any opening of the firearm and deposited at the vicinity of point of shooting.
\end{abstract}

Results: This study emphasized on the examination of the soot/particles produced and pattern distribution of GSR deposited on white cotton cloth target at varying shooting distances (from 3 to $50 \mathrm{~cm}$ ) using a video spectral comparator. Pattern distribution and GSR particle density are the main factors in determining the shooting distances in clothing. Principle component analysis (PCA) and hierarchical clustering analysis (HCA) were used to classify firearms; the differences in the GSR pattern distribution are highly recognizable. This study showed that the relationship between the GSR particle dispersion and shooting distance was proportionally linear. The results obtained from the shooting test showed that the diameter of GSR distribution and the amount of residues being deposited from shots fired decreased at distances greater than $21 \mathrm{~cm}$.

Conclusion: This study will help the investigators in determining the shooting distances and evaluating the firearms used. There is a promising method for examination of GSR pattern on the target material which is also important for firing distance estimation.

Keywords: Gunshot residue, Pattern distribution, Particle dispersion, Close range shooting distance, Principle component analysis, Hierarchical cluster analysis

\section{Background}

The presence of gunshot residue (GSR) on a suspect's clothing is an important clue for the confirmation or rejection of a court testimony. In order to fulfil the requirement of the courts, the definitive identification becomes a major topic in forensic analysis. Thus, the

\footnotetext{
* Correspondence: Zainihar@uitm.edu.my

'School of Chemistry and Environment, Faculty of Applied Sciences,

Universiti Teknologi MARA, 40450 Shah Alam, Selangor, Malaysia

Full list of author information is available at the end of the article
}

study of GSR has become imperative in forensic examination since decades ago. One of the critical incidents concerning gunshot fatalities such as suicide, homicide or accidental firing is an estimation of firing range (Brown et al. 1997). Indeed, the relationship between the distance of individual who has been shot from the firearm and the corresponding soot pattern on victim's clothes may help in crime scene investigation. The pattern and density of GSR is varied due to the complexity of the firing process such as distance and type of 
firearms. The estimated number of particles, the mutual proportions of the GSR chemical classes and size of GSR particle on the sample's cloth varied with the distance from the fired gun (Brożek-Mucha 2009).

While there are studies which focused on analysing the organic and inorganic GSR (Schwoeble and David 2000; Dalby et al. 2010; Goudsmits et al. 2015), minimal research has been conducted on pattern distribution of GSR that are formed from different firearms (BrożekMucha 2009). Therefore, the aim of this study was to analyse the pattern distribution of GSR at different shooting distances using different four types of firearms. The different firearms gave different pattern distribution of GSR and its particle dispersion on the cloth material (Ditrich 2012). According to Botello et al. (2013), the maximum distance travelled by GSR decreased as burn rate of propellant increased. Generally, GSR is projected from the muzzle of firearm in a roughly pattern, and the larger particles will travel at a longer distance as compared to the smaller particles through air resistance before at halt on sample cloth (Rowe 2005). Moreover, as shooting distances increase, only heaviest particles such as grains from burnt and unburnt propellant reach the target (Blakey et al. 2017). Furthermore, Fojtášek et al. (2003) stated that due to various formation of the GSR shapes, sizes and amount of GSR which depended on the type of weapon, a characteristic soot pattern may help to determine the fired gun.

With this respect, this study explored the potential of video spectral comparator (VSC) as a simple tool for visualizing the pattern distribution of GSR. VSC is a very powerful imaging instrument used for imaging the GSR particles. Two important features of VSC are the spot light source and signal integration that permit the detection captures of even weak luminescence within the infrared portion of the spectrum (Mokrzycki 1999). In addition, VSC is able to detect and capture gunshot powder burnt pattern on dark clothing that requires minimal handling of the evidence (Atwater et al. 2006). This gunshot powder burnt pattern could instantly be viewed, saved and printed, and no interference would be encountered by bloodstains (López-López and GarcíaRuiz 2014; Bailey 2007). Here, the images of pattern distribution on white cotton cloth were recorded to distinguish the different patterns of the firearms studied.

Recently, many researches in analysing chemical evidence with implementation of chemometrics methods have been published. Chemometric analysis simplified the mass analytical and chemical data to more understanding designs (Kumar and Sharma 2018). The pattern recognition such as principle component analysis (PCA) and hierarchical cluster analysis (HCA) helps in grouping the analysis samples by their similarity or dissimilarity. PCA is most frequently used in various studies including forensic analysis. It is because PCA is an important step in analysing the data (Hibbert 2009; Cordella 2012). In order to detect pattern in dataset, PCA plays an important role in reducing the dimension of the dataset without losing any information from original data.

Whereas HCA is an exploratory technique that is used for grouping the samples according to their similarity of characteristics, HCA shows simple relationship in clustering the samples, where the smaller the distance between samples, the more similar to each other (BrozekMucha and Jankowicz 2001). This manuscript shows the novelty in use of mean data of GSR particle dispersion combined with chemometric analysis, PCA and HCA that has been discriminating the firearms into different classes. Thus, helps the investigator in predicting the firearms used.

\section{Methods}

\section{Effect of shooting distance}

A series of test shots were performed in an indoor shooting range with the ventilation turned off. Material for shooting target is white cotton fabrics with the size of $30 \mathrm{~cm} \times 30 \mathrm{~cm}$. Four types of firearms, (A) revolver brand Colt Police Positive, (B) revolver brand Smith \& Wesson 38 Special, (C) semiautomatic pistol brand Sig Sauer P226 and (D) semiautomatic pistol brand Walther P99, were used in this study. The shootings were performed at eight different shooting distances of 3, 9, 15, 21, 30, 40, 45 and $50 \mathrm{~cm}$ using 0.38 inch (for A and B) and $9 \times 19 \mathrm{~mm}$ Syarikat Malaysia Explosive (SME) ammunitions (for $\mathrm{C}$ and $\mathrm{D}$ ). After the firing test, the pattern distribution of GSR was visually examined using video spectral comparator (VSC) 5000 from Foster and Freeman (UK). The optical condition VSC used in this study was incandescent filament lamp with visible spectrum of $530 \mathrm{~nm}$ wavelength (longpass filter).

\section{Number of GSR particle estimation}

In order to estimate the particle dispersion produced from different firearms during shooting incidents, the particle density $\left(A=\pi r^{2}\right)$ of GSR was measured (Fig. 1) according to Hofer et al. (2017). The number of GSR particles found in target materials was counted within ar1 and ar2 ( $\operatorname{ar} 1$ = area with radius, $\mathrm{r} 1$ and $\operatorname{ar} 2=$ area with radius, $r 2$ ), with the bullet hole as the centre of the circles. The length of the radius, $r 1$, is based on the larger soot that can be found from shooting materials. Three replicates per distance ( 8 distances $\times 4$ firearms) were prepared for measurements. The abbreviation for the approximate corresponding GSR particles is as follows:

$$
\begin{aligned}
& n=\text { number of particles } \\
& a=\text { area }=\pi r^{2} \\
& r=\text { radius }(\text { e.g. } \mathrm{r} 1=0-5 \mathrm{~cm} ; \mathrm{r} 2=5-13 \mathrm{~cm})
\end{aligned}
$$




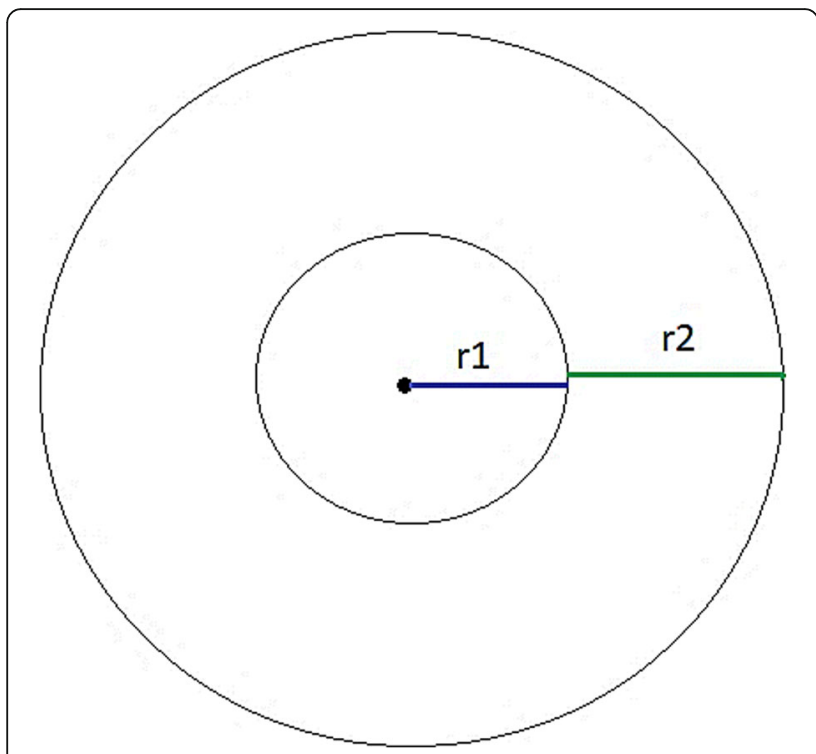

Fig. 1 Schematic description for particle quantification

Total $=\mathrm{r} 1+\mathrm{r} 2($ rtotal $=13 \mathrm{~cm})$

Density $=n$ /area

D1 = density for ar1

D2 = density for ar2

\section{Chemometric study}

For statistical analysis, additional of two different brands of ammunition $9 \times 19 \mathrm{~mm}$ Winchester (WIN) and $9 \times$ $19 \mathrm{~mm}$ Sellier and Bellot (S\&B) were shot from pistol C and $\mathrm{D}$. The nomenclature of samples was systematically named by Types of firearm_calibre, brand of ammunition such as (C_9WIN and C_9S\&B) and Walther (D_ 9WIN and D_9S\&B). The mean data of particle density were used for principle component analysis (PCA) and hierarchical clustering analysis (HCA). Chemometric analysis was done by XLSTAT software (Addinsoft Inc. New York, NY, USA).

\section{Results}

\section{Pattern distribution of GSR}

One of the important aspects that need to be considered during ballistic investigations is shooting distance. Several series of experiment were performed to investigate the pattern distribution and dispersion of GSR particles at short distances. In order to minimize the factors that affect the pattern distribution of GSR, the external factors such as wind and angles of shooting were eliminated. Due to the limited samples of evidence at real crime scene, VSC is a suitable instrument to analyse the sample without destructing the evidence. Even though this experimental study was limited to only one brand of ammunition, the findings proved that the pattern of soot and GSR dispersion are unique for each firearm. At close range of shooting distances, the GSR particles reached the target and caused blackening or sooting. Apparently, different pattern of blackening soot zone around the bullet entrance was formed using different firearm (Fig. 2). The pattern of soot formed from the revolver showed the thickness of the soot due to the closeness of the target to the cloud of residues which were expelled earlier than the bullet. At $3 \mathrm{~cm}$ shooting distance, (a_.38SME) and (b_.38SME) revolver produce highly dense and fully blackening soot zone around bullet hole up to $10 \mathrm{~cm}$ of soot diameter, while (c_9SME) and (d_9SME) pistol have up to $9 \mathrm{~cm}$ diameter of dense black zone around bullet hole.

From the results in Fig. 3, (A_.38SME) produced larger soot on target materials compared to other firearms at 9 $\mathrm{cm}$ of shooting distance. On the contrary, only few particles of GSR from (B_.38SME) revolver were found on target materials compared to (A_.38SME) and both pistols. At $15 \mathrm{~cm}$ of shooting distance, the diameter of blackening soot from revolver was reduced to $2 \mathrm{~cm}$. Meanwhile, the disappearance of soot for both pistols had occurred.

Figure 4 further proof that different distances produced significantly distinguished soot pattern. Although there was no appearance of soot from (C_9SME) and (D_9SME) at $21 \mathrm{~cm}$ of shooting distance, the soot can still be found from the shoot test of (A_.38SME) and (B_ .38SME) revolvers. Subsequently, increasing the shooting distance to $30 \mathrm{~cm}$ showed the disappearance of blackening soot around the entrance. This situation occurred in shooting test using all types of firearms except for (A $.38 \mathrm{SME}$ ) revolver. In addition, at $30 \mathrm{~cm}$ of shooting distance, the pattern showed a reducing amount of GSR particles on target material and diameter of distribution. The total amount of GSR particles presence in target materials may vary between the distances. Moreover, at $40 \mathrm{~cm}$ and $45 \mathrm{~cm}$ of shooting distance, the length of GSR particle dispersion became shorter than $12 \mathrm{~cm}$ and less particles of GSR were found on target material. At 50 $\mathrm{cm}$ of shooting distance, only a small amount of GSR particles can be found from all types of firearm.

\section{Particle dispersion on target material}

This study found that (A_.38SME) revolver produced more particles of GSR at shorter shooting distances compared to (B_.38SME) revolver as well as both pistols of (C_9SME) and (D_9SME). The amount of GSR particles found on cloth materials were varied at shooting distances as well as from different firearms. The amount of GSR particles decreased as shooting distances increased. There were about 1548 and 1256 particles of GSR from (A_.38SME) and (B_.38SME) respectively found at $3 \mathrm{~cm}$ shooting distance. As shown in Fig. 5, approximately 1349 and 1435 GSR particles produced from 


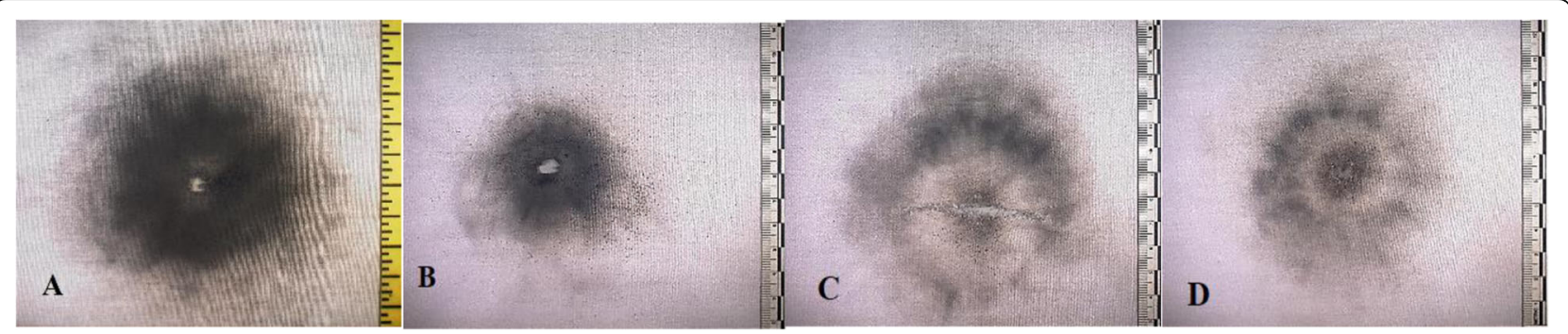

Fig. 2 Different pattern distribution of soots and GSR particles using firearms (a_.38SME), (b_.38SME). (c_9SME) and (d__9SME) at $3 \mathrm{~cm}$ of shooting distances

pistols (C_9SME) and (D_9SME) were found at $3 \mathrm{~cm}$ shooting distance. However, at $21 \mathrm{~cm}$ shooting distance, pistol (D_9SME) had 1528 total particle distribution of GSR higher than other firearms. Approximately 1351, 1086 and 1259 of total particle distribution were produced from revolver (A_.38SME) and (B_.38SME) and pistol (C_9SME) respectively at $21 \mathrm{~cm}$ shooting distance. As shooting distance was increased to $50 \mathrm{~cm}$, the particles in the area r2 from (A_.38SME), (B_.38SME) and pistol (C_9SME) had disappeared. In total, only about 300-400 particles of GSR can be found at $50 \mathrm{~cm}$ of shooting distance.

Table 1 and Table 2 show the particle density of GSR formed from different firearms at different shooting distances. The mean values and standard deviations of GSR particle densities on the selected area ( $\mathrm{r} 1$ and $\mathrm{r} 2)$ were measured. At $3 \mathrm{~cm}$ of shooting distance, (A_.38SME) revolver formed higher density of GSR followed with (D_9SME) pistol, (C_9SME) pistol and (B_.38SME) revolver with $15.9,15.6,14.8$ and 12.6 of total density (Dtotal) respectively. All the firearms show the amount of particle density (D1 and D2) at $\mathrm{r} 1$ and $\mathrm{r} 2$ continuing decreased as the shooting distance increase. At $30 \mathrm{~cm}$ of shooting distance, (B_.38SME) shows disappearance of GSR particles on the area of radius $\mathrm{r} 2$. Meanwhile, particle density (D2) are loss from both (A_.38SME) and (C_9SME) at $45 \mathrm{~cm}$ of shooting distance. Particle density (D2) of (D_9SME) had disappearance at $50 \mathrm{~cm}$ of shooting distance.

At $50 \mathrm{~cm}$ shooting distance, the GSR particles significantly showed the total density (Dtotal) of 3.2, 3.2, 3.1 and 3.4 for revolver (A_.38SME) and (B_.38SME) and pistol (C_9SME) and (D_9SME) respectively. It was still possible to detect the GSR particles at distances longer

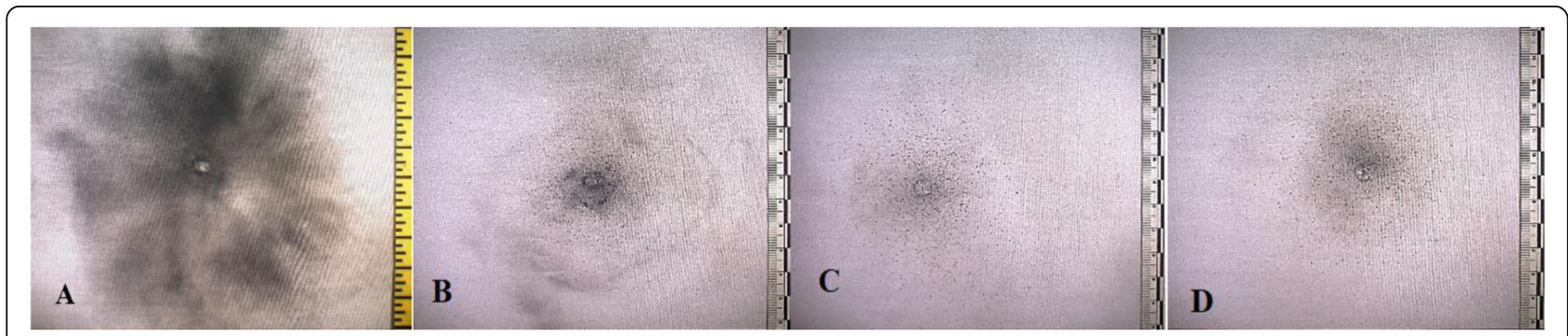

(a)

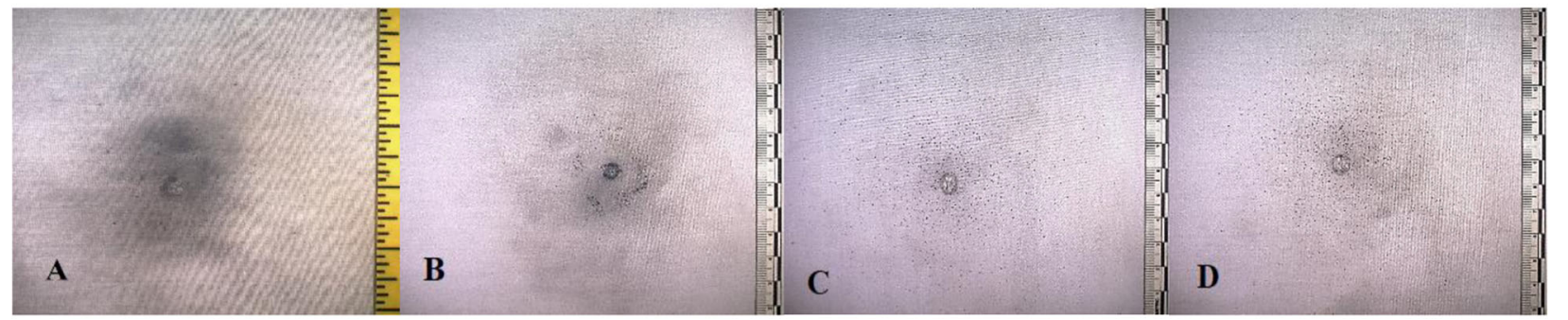

(b)

Fig. 3 Pattern distribution of soot and GSR particles: In the $x$-axis scale: (A_.38SME), (B_.38SME), (C_9SME) and (D_9SME). In the $y$-axis scale: shooting distances of $\mathbf{a} 9 \mathrm{~cm}$ and $\mathbf{b} 15 \mathrm{~cm}$ 


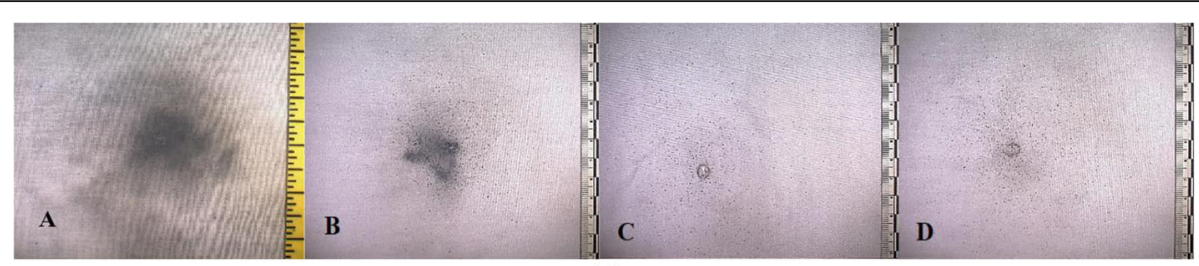

(a)

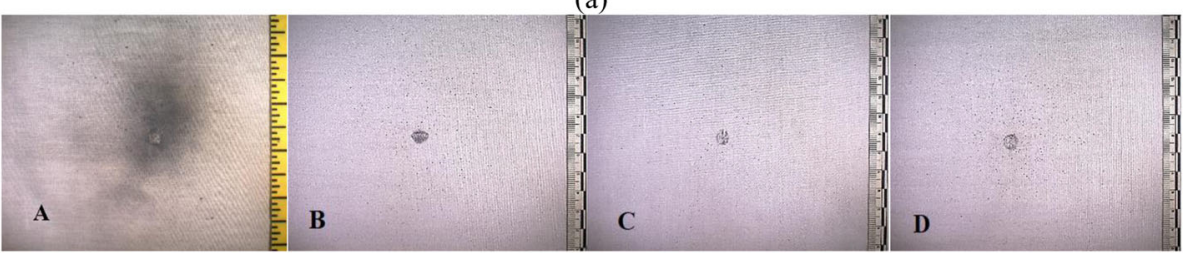

(b)

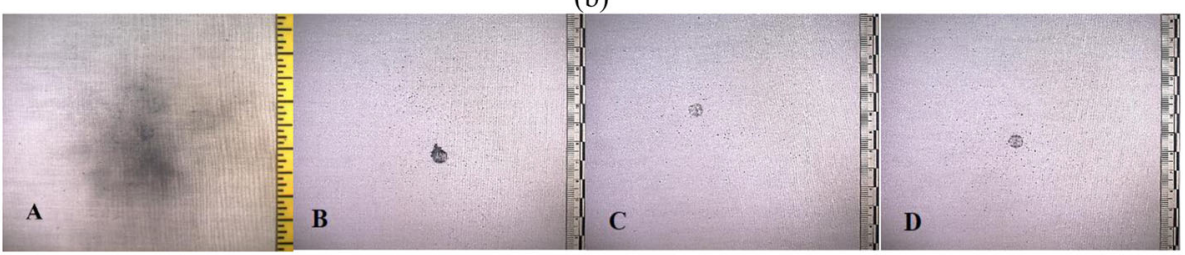

(c)

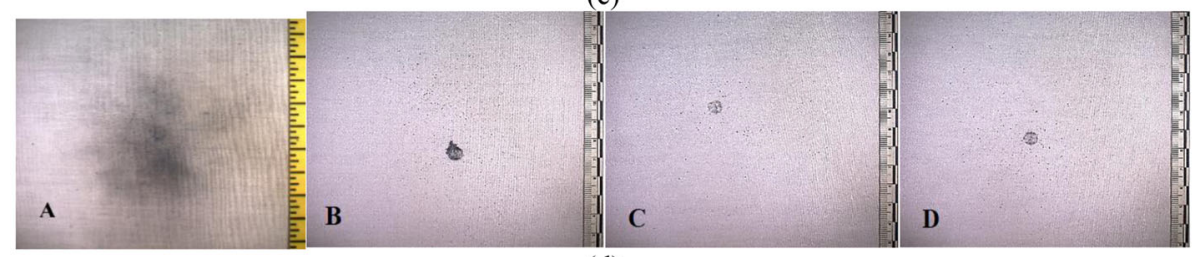

(d)

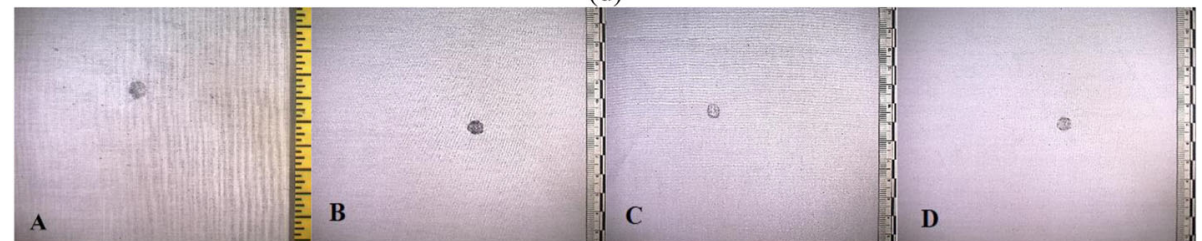

(e)

Fig. 4 Pattern distribution of soot and GSR particles: In the $x$-axis scale: (A_.38SME), (B_.38SME), (C_9SME) and (D_9SME) (A_.38SME), (B_.38SME), (C_9SME) and (D_9SME). In the $y$-axis scale: shooting distances of a 21, b 30, c 40, d 45 and e $50 \mathrm{~cm}$

\section{Firearms vs Distances}

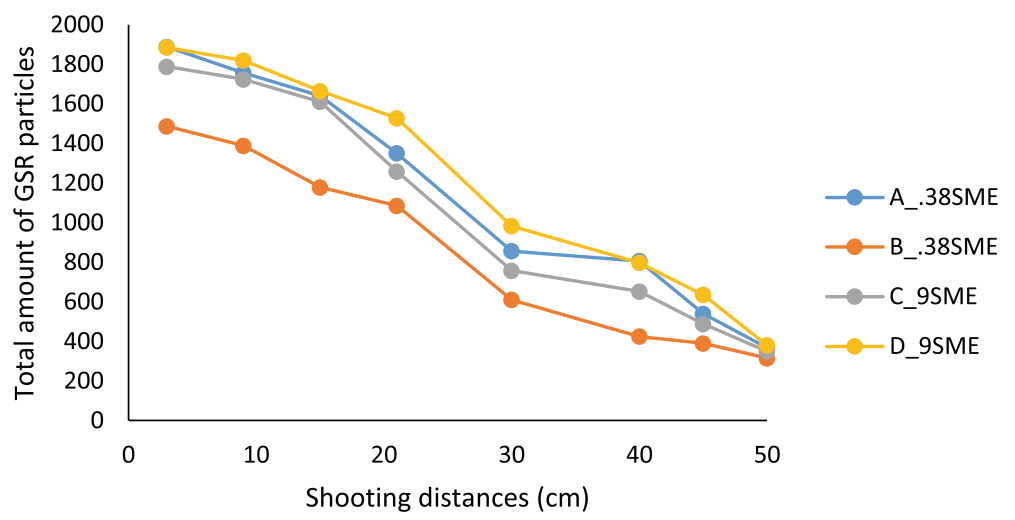

Fig. 5 Total amount of GSR particles from different types of firearms vs. shooting distance curves 
Table 1 Density of GSR particles vs. shooting distance data for (A_.38SME) and (B_.38SME) revolver at different shooting distances

\begin{tabular}{|c|c|c|c|c|c|c|}
\hline \multirow{3}{*}{$\begin{array}{l}\text { Shooting } \\
\text { distance } \\
\text { (cm) }\end{array}$} & \multicolumn{6}{|c|}{ Density of GSR particles } \\
\hline & \multicolumn{3}{|l|}{ (A_.38SME) } & \multicolumn{3}{|l|}{ (B_.38SME) } \\
\hline & D1 & D2 & Dtotal & D1 & D2 & Dtotal \\
\hline 3 & $13.7 \pm 0.01$ & $2.2 \pm 0.01$ & $15.9 \pm 0.01$ & $11.1 \pm 0.01$ & $1.5 \pm 0.00$ & $12.6 \pm 0.01$ \\
\hline 9 & $12.3 \pm 0.01$ & $2.1 \pm 0.01$ & $14.4 \pm 0.01$ & $10.5 \pm 0.00$ & $1.3 \pm 0.01$ & $11.8 \pm 0.00$ \\
\hline 15 & $12.0 \pm 0.01$ & $1.9 \pm 0.01$ & $13.9 \pm 0.01$ & $8.9 \pm 0.01$ & $1.1 \pm 0.01$ & $10.0 \pm 0.00$ \\
\hline 21 & $9.8 \pm 0.00$ & $1.6 \pm 0.00$ & $11.4 \pm 0$ & $8.5 \pm 0.00$ & $0.8 \pm 0.00$ & $9.3 \pm 0.01$ \\
\hline 30 & $6.3 \pm 0.01$ & $1.0 \pm 0.00$ & $7.3 \pm 0.01$ & $5.4 \pm 0.00$ & - & $5.4 \pm 0.00$ \\
\hline 40 & $5.9 \pm 0.01$ & $0.9 \pm 0.00$ & $6.8 \pm 0.01$ & $3.8 \pm 0.00$ & - & $3.8 \pm 0.00$ \\
\hline 45 & $4.8 \pm 0.01$ & - & $4.8 \pm 0.01$ & $3.4 \pm 0.00$ & - & $3.4 \pm 0.00$ \\
\hline 50 & $3.2 \pm 0.01$ & - & $3.2 \pm 0.01$ & $3.2 \pm 0.00$ & - & $3.2 \pm 0.00$ \\
\hline
\end{tabular}

than $50 \mathrm{~cm}$; however, it depended on external factors such as wind, type of firearms and ammunition.

\section{Chemometric analysis}

Despite measuring the relationship between firearms and particle density on different shooting distances, the study was further analysed by PCA and HCA. PCA was performed using the mean data of GSR particles that were produced from different types of firearms. The PCA results were visualized using a score plot of F1 versus F2 with variance of $89.08 \%$ and $8.18 \%$ respectively (Fig. 6).

These data were further analysed for HCA, which produced result by class or cluster. The HCA results of the analysed samples shows to be significantly similar with the result performed by PCA. The samples were classified into three classes, in which sample B_.38SME was solely clustered to $\mathrm{C} 2$ that separates itself from others samples. All the samples from $\mathrm{C}$ pistol (C_9SME, $\mathrm{C}_{-}$ 9WIN and C_9S\&B) were grouped under the same class, C3. Meanwhile, the A_.38SME sample that is located near the firing samples from D pistol (D_9SME, D_ 9WIN and D_9S\&B) was assembled into one class, C1. $\mathrm{C} 1$ resulted in 0.9325 within class variance, with an average distance of 0.7531 , while C3 have 0.2582 of maximum distance and 0.3021 of average distance within class.

\section{Discussion}

The pattern distribution of GSR can be discussed in three factors, which are scorching, blackening or sooting pattern and GSR particle distribution (Heard 2008). In this study, scorching on cloth materials formed at $3 \mathrm{~cm}$ of shooting distance for all types of firearms. The fibres around the bullet hole were shrivelled and melted. However, the scorching effect cannot be seen by naked eyes as shooting distance increased. Scorching caused by the gases that were produced from the muzzle during firing leave the barrel at higher temperature before it hits the target material. Consequently, different pressures of gases that hit the target material have different effects of scorching. Despite gases formed during firing, the scorching effect is also caused by the condition of target surface and propellant types (Heard 2008).

In spite of that, the blast flame released from the barrel during the firing caused the burning of the fabrics and formed the blackening soot. The pattern of the soot

Table 2 Density of GSR particles vs. shooting distance data for (C_9SME) and (D_9SME) pistol at different shooting distances

\begin{tabular}{|c|c|c|c|c|c|c|}
\hline \multirow{3}{*}{$\begin{array}{l}\text { Shooting } \\
\text { distance } \\
\text { (cm) }\end{array}$} & \multicolumn{6}{|c|}{ Density of GSR particles } \\
\hline & \multicolumn{3}{|l|}{ (C_9SME) } & \multicolumn{3}{|l|}{ (D_9SME) } \\
\hline & D1 & D2 & Dtotal & D1 & D2 & Dtotal \\
\hline 3 & $11.9 \pm 0.01$ & $2.9 \pm 0.01$ & $14.8 \pm 0.01$ & $12.7 \pm 0.01$ & $2.9 \pm 0.00$ & $15.6 \pm 0.00$ \\
\hline 9 & $11.6 \pm 0.04$ & $2.7 \pm 0.03$ & $14.3 \pm 0.01$ & $12.2 \pm 0.01$ & $2.8 \pm 0.02$ & $15.0 \pm 0.01$ \\
\hline 15 & $11.0 \pm 0.01$ & $2.4 \pm 0.01$ & $13.4 \pm 0.01$ & $11.2 \pm 0.00$ & $2.6 \pm 0.00$ & $13.8 \pm 0.01$ \\
\hline 21 & $8.6 \pm 0.02$ & $1.9 \pm 0.01$ & $10.5 \pm 0.01$ & $10.7 \pm 0.01$ & $2.1 \pm 0.01$ & $12.8 \pm 0.00$ \\
\hline 30 & $5.4 \pm 0.01$ & $0.9 \pm 0.01$ & $6.3 \pm 0.01$ & $7.2 \pm 0.01$ & $1.1 \pm 0.01$ & $8.3 \pm 0.00$ \\
\hline 40 & $5.0 \pm 0.01$ & $0.6 \pm 0.01$ & $5.6 \pm 0.00$ & $6.0 \pm 0.00$ & $0.8 \pm 0.00$ & $6.8 \pm 0.01$ \\
\hline 45 & $4.3 \pm 0.01$ & - & $4.3 \pm 0.01$ & $5.2 \pm 0.01$ & $0.3 \pm 0.01$ & $5.5 \pm 0.01$ \\
\hline 50 & $3.1 \pm 0.01$ & - & $3.1 \pm 0.01$ & $3.4 \pm 0.02$ & - & $3.4 \pm 0.01$ \\
\hline
\end{tabular}



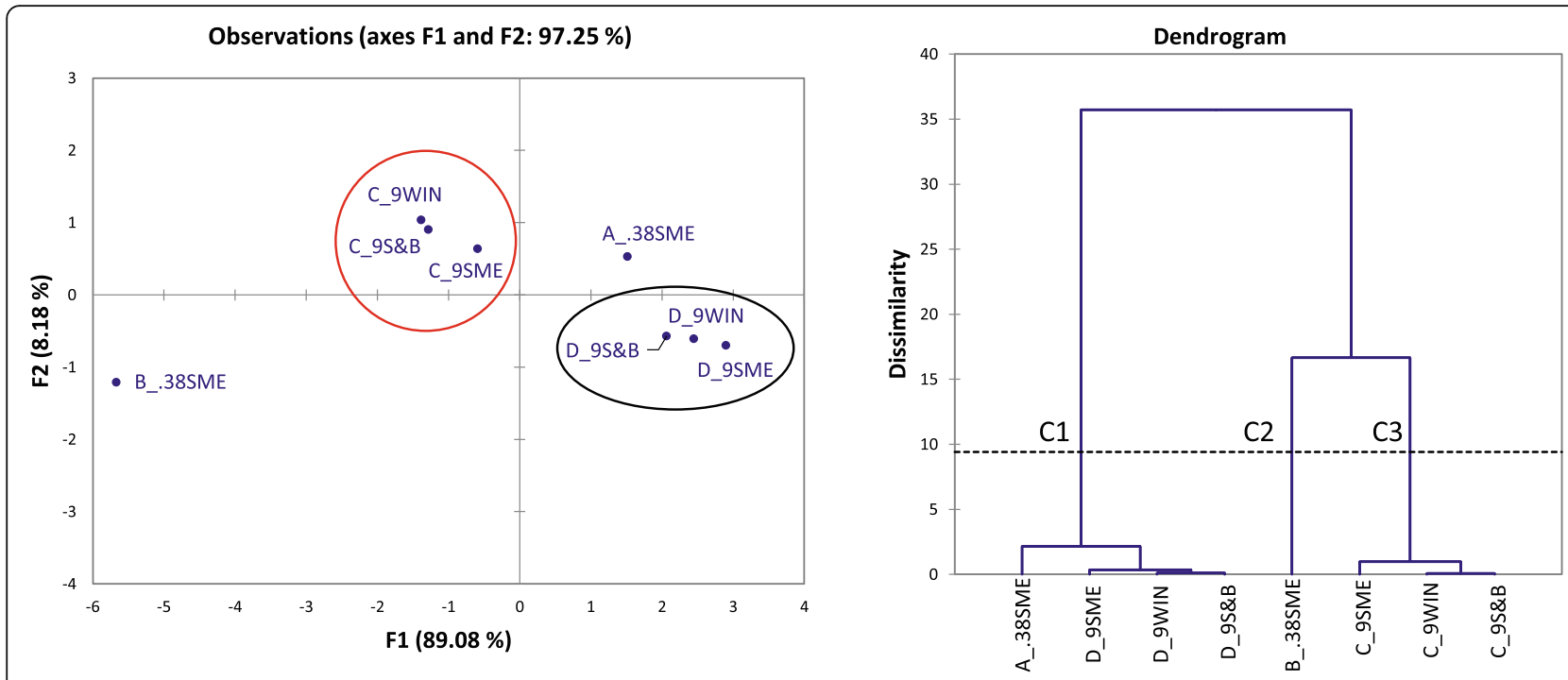

Fig. 6 PCA score plot of shooting test using different types of firearms (right). HCA dendrogram of firearms (left)

gave the information in determining the length of barrels. The short barrel produced a thick and larger soot halo compared to the long barrel (Brown et al. 1997). This explained the differences between diameters of soot produced from different firearms. In this study, (A) revolver with barrel length of 4.0 inch has larger soot compare to (B) revolver with barrel length of 4.25 inch. However, when comparing (B) revolver to (D) pistol which have similar barrel length, it shows that (B) revolver has larger soot pattern. In this situation, the internal pressure of firearms and the weight of propellant should be considered. Ideally, the lower pressure of firearm causes the higher incomplete combustion of carbonaceous materials, which formed the blackening zone (Heard 2008). Revolver produced low pressure of firing the ammunition via its single or double mechanism compare to self-loading mechanism of pistol. Besides, 0.38 inch SME ammunition consists of $147 \mathrm{~g}$ propellant compare to $9 \mathrm{~mm}$ SME ammunition with $124 \mathrm{~g}$ propellant. In short, despite the barrel length and ammunition types, the weight of propellant and internal pressure generated by cartridge and firearms also contribute in differences patterns of blackening soot on materials.

Meanwhile, it was found that pistol (C_9SME) and (D_ 9SME) produced a huge amount of residue which dispersed up to $15 \mathrm{~cm}$ of diameter from the entrance bullet. However, the residues from revolver can only be found around the soot zone which assembled near the bullet entrance. This is due to the fact that the particles from the ammunition have vaporized since it took a longer distance to reach the target materials. Besides, the weight of propellant and types of ammunition affect the dispersion of GSR particles. Therefore, the particles that successfully reached the target were only found at smaller radius from the bullet hole.
Above all, the determination of shooting distance depended on many variables such as the barrel length of firearms, ammunition and target materials, among others. Interestingly, it is noted that different firearms with almost identical barrel length (4.0 to 4.4 inch) used in this study produced different pattern distribution and particles of GSR formed through different shooting distance. Even though the barrel length between the firearms is in minimal differences $( \pm 0.4$ inch), the pattern of soot and distribution of GSR showed dissimilarity to each other. Thus, the different firearms gave different pattern of GSR distribution.

Chemometric study using PCA and HCA indicates a clear separation among the type of firearms. It found that the samples were roughly divided into four groups. The positive correlation between the samples gave the information that samples have the same characteristics such as types of firearms or ammunitions used. Samples that are fired from the same firearms such as C_9SME, C_9WIN and C_9S\&B are shown to be positively correlated. This also occurred to samples from D pistol (D_ 9SME, D_9WIN and D_9S\&B), in which the score plot shows that the samples are located near to one another. Meanwhile, B_.38SME is shown to be negatively correlated with A_.38SME. It means that firing the same ammunition with different firearms produces dissimilarity of GSR particle density, while GSR produced from the same firearms shows similar characteristics.

\section{Conclusions}

The findings of the present study can be potentially used for evidence recovery in real case investigations. In this study, visualised technique using VSC has shown that different pattern distributions formed from different 
firearms gave lots of information such as soot and length of distribution as well as amounts of GSR particle produced. This study shows the dissimilarity of firing test between the firearms. Thus, it helps the investigators in determining the shooting distances and evaluating the firearms used. This study also reveals that the length barrel of the firearms which was almost identical to each other gave different pattern distributions of GSR as well as the number of particles formed during firing. However, due to the manual counting technique, the particle measurement was approximately considered. Last but not the least, the statistical approach of PCA and HCA management in grouping the samples into similar characteristics helps in determining the types of firearm used.

\section{Nomenclature}

Types of firearm_calibre, brand of ammunition A_.38SME: Colt_0.38" Syarikat Malaysia Explosive B_.38SME: Smith \& Wesson_0.38" Syarikat Malaysia Explosive C_9SME: Sig Sauer_9mm Syarikat Malaysia Explosive C_9WIN: Sig Sauer_9mm Winchester C_9S\&B: Sig Sauer_9mm Sellior\&Bellot D_9SME: Walther_9mm Syarikat Malaysia Explosive D_9WIN: Walther_9mm Winchester D_9S\&B: Walther_9mm Sellior\&Bellot aArea $n$ Number of particles $r$ Radius D1 Density for ar1 D2 Density for ar2

\section{Abbreviations}

GSR: Gunshot residue; VSC: Video spectral comparator; PCA: Principle component analysis; HCA: Hierarchical clustering analysis; (A): Revolver brand Colt Police Positive; (B): Revolver brand Smith \& Wesson 38 Special; (C): Semiautomatic pistol brand Sig Sauer P226; (D): Semiautomatic pistol brand Walther P99; SME: Syarikat Malaysia Explosive; WIN: Winchester; S\&B: Sellior\&Bellot

\section{Acknowledgements}

The authors gratefully acknowledged and expressed thankfulness to the Royal Malaysian Police for giving the permission to use their facilities in Ballistic Department, Forensic Laboratory Cheras, Malaysia. Furthermore, the authors also thanked ASP Nik Norhisham for fruitful discussion and precious advice.

\section{Authors' contributions}

SNJ analysed and interpreted the shooting data and wrote the manuscript. ZNZ supervised SNJ's research work and drafted, edited, and submitted the manuscript. MSMS prepared the shooting materials and performed the shooting test. MIAH mooted the idea and designed and co-supervised SNJ's work. All authors read and approved the final manuscript.

\section{Funding}

Not applicable. This research is not funded under any funder/schemes.

\section{Availability of data and materials}

The datasets used and/or analysed during the current study are available from the corresponding author on reasonable request.

\section{Declarations}

Ethics approval and consent to participate

Not applicable. No human and animal were involved as samples in this work.

Consent for publication

Not applicable.

\section{Competing interests}

The authors declared that they have no competing interest.

\section{Author details}

${ }^{1}$ School of Chemistry and Environment, Faculty of Applied Sciences, Universiti Teknologi MARA, 40450 Shah Alam, Selangor, Malaysia. ${ }^{2}$ Forensic Laboratory Royal Malaysia Police, 43200 Cheras, Malaysia.

Received: 12 November 2020 Accepted: 9 May 2021

Published online: 21 May 2021

\section{References}

Atwater CS, Durina ME, Durina JP, Blackledge RD (2006) Visualization of gunshot residue patterns on dark clothing. J Forensic Sci 51(5):1091-1095. https://doi. org/10.1111/j.1556-4029.2006.00226.x

Bailey JA (2007) Digital infrared photography to develop GSR patterns. Aust J Forensic Sci 39(1):33-40. https://doi.org/10.1080/00450610701324932

Blakey LS, Sharples GP, Chana K, Birkett JW (2017) Fate and behaviour of gunshot residue-a review. J Forensic Sci 63(1):9-19. https://doi.org/10.1111/1556-402 9.13555

Botello, D., Deskins, D., Staton, P., Rushton, C., \& Copeland, J. (2013). The effects of powder, barrel length \& velocity on distance determination. https://www.ma rshall.edu/forensics/files/Distance-Determination. Accessed Feb 2020.

Brown TD, Michas P, Williams RE, Dawson G, Whitecloud TS, Barrack RL (1997) The impact of gunshot wounds on an orthopaedic surgical service in an urban trauma center. J Orthop Trauma 11(3):149-153. https://doi.org/10.1 097/00005131-199704000-00002

Brożek-Mucha Z (2009) Distribution and properties of gunshot residue originating from a Luger $9 \mathrm{~mm}$ ammunition in the vicinity of the shooting gun. Forensic Sci Int 183(1-3):33-44. https://doi.org/10.1016/j.forsciint.2008.10.010

Brozek-Mucha Z, Jankowicz A (2001) Evaluation of the possibility of differentiation between various types of ammunition by means of GSR examination with SEM-EDX method. Forensic Sci Int 123(1):39-47. https:// doi.org/10.1016/s0379-0738(01)00518-7

Cordella CB (2012) PCA: the basic building blocks of chemometric. In: Analytical chemistry. https://doi.org/10.5772/51429

Dalby O, Butler D, Birkett JW (2010) Analysis of gunshot residue and associated materials - a review. J Forensic Sci 55(4):924-943. https://doi.org/10.1111/j.1 556-4029.2010.01370.x

Ditrich H (2012) Distribution of gunshot residues-the influence of weapon type. Forensic Sci Int 220(1-3):85-90. https://doi.org/10.1016/j.forsciint.2012.01.034

Fojtášek L, Vacínová J, Kolář P, Kotrlý M (2003) Distribution of GSR particles in the surroundings of shooting pistol. Forensic Sci Int 132(2):99-105. https://doi. org/10.1016/S0379-0738(03)00018-5

Goudsmits E, Sharples GP, Birkett JW (2015) Recent trends in organic gunshot residue analysis. TrAC Trends Anal Chem 74:46-57. https://doi.org/10.1016/j. trac.2015.05.010

Heard BJ (2008) Handbook of firearms and ballistics: examining and interpreting forensic evidence, 2nd edn. West Sussex, UK. https://doi.org/10.1002/97804 70694589

Hibbert DB (2009) Chemometric analysis of sensory data. In: Brown S, Tauler R, Walczak B (eds) Comprehensive Chemometrics (2nd Edition). Elsevier, pp $377-424$

Hofer R, Graf S, Christen S (2017) The use of unburned propellant powder for shooting-distance determination. Part I: Infrared luminescence. Forensic Sci Int 273:10-19. https://doi.org/10.1016/j.forsciint.2017.01.019

Kumar R, Sharma V (2018) Chemometrics in forensic science. TrAC Trends Anal Chem 105:191-201. https://doi.org/10.1016/j.trac.2018.05.010

López-López M, García-Ruiz C (2014) Recent non-chemical approaches to estimate the shooting distance. Forensic Sci Int 239:79-85. https://doi.org/1 0.1016/j.forsciint.2014.03.023 
Mokrzycki GM (1999) Advances in document examination: the video spectral comparator 2000. Forensic Sci Commun 1(3) https://www.ncjrs.gov/app/adva nceindocumentexamination. Accessed Feb 2020

Rowe WF (2005) Firearms identification. In: Saferstein R (ed) Forensic Science Handbook, Vol. II, 2nd edn. Pearson Education, Prentice Hall Schwoeble AJ, David LE (2000) Current methods in forensic gunshot residue analysis, 1st edn. Boca Raton, Florida. https://doi.org/10.1201/9781420042573

\section{Publisher's Note}

Springer Nature remains neutral with regard to jurisdictional claims in published maps and institutional affiliations.

\section{Submit your manuscript to a SpringerOpen ${ }^{\circ}$ journal and benefit from:}

- Convenient online submission

- Rigorous peer review

- Open access: articles freely available online

- High visibility within the field

- Retaining the copyright to your article

Submit your next manuscript at $\boldsymbol{\nabla}$ springeropen.com 